\title{
Subjective well-being and Citizenship dimensions according to individualism and collectivism beliefs among Polish adolescents
}

\author{
Anna M. Zalewska ${ }^{1 \cdot A, C, D, E, F, G}$, Agnieszka Zawadzka $a^{2 \cdot B, F}$ \\ 1: SWPS University of Social Sciences and Humanities, Faculty in Poznan, Poland \\ 2: SWPS University of Social Sciences and Humanities, Faculty in Wrocław, Poland
}

\section{BACKGROUND}

The aim of the research is to analyse pleasant (subjective well-being - SWB) and meaningful life (Citizenship dimensions) in the context of Horizontal and Vertical Individualism $(\mathrm{HI}, \mathrm{VI})$ or Collectivism $(\mathrm{HC}, \mathrm{VC})$ values (individual beliefs) among adolescents living in the culture "in between individualism and collectivism".

\section{PARTICIPANTS AND PROCEDURE}

Second-year high (111) and secondary (98) school students filled in the Horizontal and Vertical Individualism and Collectivism Questionnaire, the Citizenship Behaviour Questionnaire, and SWB (Subjective Happiness Scale, Satisfaction with the Life Scale, Mood Questionnaire, Ladder of Need Scales). Participants were recruited in schools.

\section{RESULTS}

Subjective well-being positively correlated with all Citizenship dimensions except Political Activity. All values predicted SWB, but higher VI predicted lower SWB and was not linked to Citizenship. Citizenship dimensions oriented to general good were predicted by Collectivism values, and those including personal benefits were predicted by $\mathrm{HI}$ and Collectivism values. Subjective well-being mediated relations between $\mathrm{HC}$ and Social Activity, and between $\mathrm{HC}$, $\mathrm{HI}$ and Personal Activity. VC moderated relations between SWB and Passive as well as Semi-active Citizenship.

\section{CONCLUSIONS}

Among young Poles, pleasant life is linked with meaningful life. Individualism and Collectivism values are relatively independent, and their relations with SWB and Citizenship are complex. Higher Horizontal values facilitate the achievement of both pleasant and meaningful life, but higher VC can hinder the coherence between them. High SWB, engagement in Citizenship and links between them are required for attaining "authentic happiness" and living a truly full life; thus it is important to study variables that may influence them.

\section{KEY WORDS}

adolescents; happiness; horizontal and vertical individualism or collectivism; meaningful life

CORRESPONDING AUTHOR - Prof. Anna M. Zalewska, SWPS University of Social Sciences and Humanities,

Faculty in Poznan, 10 Kutrzeby Str., 61-719 Poznan, Poland, e-mail: azalewsk@swps.edu.pl

AUthors' CONTRibution - A: Study design - B: Data collection - C: Statistical analysis - D: Data interpretation .

E: Manuscript preparation · F: Literature search · G: Funds collection

TO CITE thIS ARTICLE - Zalewska, A. M., \& Zawadzka, A. (2016). Subjective well-being and citizenship dimensions

according to individualism and collectivism beliefs among Polish adolescents. Current Issues in Personality

Psychology, 4(3), 155-166.

RECEIVED 12.04.2016 · REVIEWED 15.05.2016 · ACCEPTED 18.07.2016 · PUBLISHED 05.08.2016 


\section{BACKGROUND}

The aim of the research is to analyse complex relationships between two components of "Authentic Happiness" - pleasant (subjective well-being - SWB) and meaningful life (six Citizenship dimensions) - in the context of Horizontal and Vertical Individualism or Collectivism orientations among adolescents. In this paper those orientations are regarded as individual beliefs of young Poles who are living in the culture "in between individualism and collectivism", with mixed elements of both individualism and collectivism. The analyses are aimed at answering the following questions:

1. What are the relations between the investigated orientations, SWB and Citizenship dimensions?

2. Which of the examined beliefs allow one to predict SWB?

3. Are relationships of the beliefs with Citizenship dimensions mediated by SWB?

4. Are relationships of SWB with Citizenship dimensions moderated by the beliefs?

\section{PLEASANT AND MEANINGFUL LIFE AS TWO COMPONENTS OF “AUTHENTIC HAPPINESS”}

According to dynamically developing positive psychology, a human being is an active and responsible individual possessing strengths (virtues and skills), seeking authentic happiness (Seligman, 2002), striving for personal growth and flourishing (Seligman, 2011). Personal growth is related to the development of skills that make it possible to achieve various aspects of authentic happiness (Zalewska \& KrzywoszRynkiewicz, 2011):

- a pleasant life (hedonistic aspect) - primarily requires the ability to evoke and control one's positive emotions related to the past, present and future (emotions and life satisfaction are included by Seligman in this life aspect);

- a good life (eudemonic aspect tied to engagement) - requires the ability to recognise and apply one's strengths in the central areas of life in order to achieve gratification and experience the joy of self-realisation following from the challenges evoking engagement, effective action and the feeling of flow;

- a meaningful life - requires the ability to use one's strengths for purposes greater than oneself, such as: knowledge (gaining or sharing), power (technology development, health services, manufacturing) or common good (law, religion, ethics, politics, democracy, serving a country, fighting fires, charity). Striving and achieving purposes greater than oneself gives meaning to one's life (it is needed by others and contributes to the common good).
In the newest version of the theory of flourishing, Seligman (2011) adds accomplishment and positive relationships with other people to the three aspects of Authentic Happiness. People can only strive to achieve one of the five elements of flourishing. However, according to Seligman (2011), achieving a full life requires cultivation of all of the aforementioned skills as well as striving to achieve all five elements of flourishing. For this reason positive relationships between all the elements are to be expected.

In this article we will focus, among other things, on the relationship between two elements of Authentic Happiness: the SWB as an indicator of a pleasant life and the Citizenship dimensions, understood here as indicators of the meaningful life, engagement in personal and social life as well as the accomplishment of purposes greater than oneself needed to make the world better.

\section{SUBJECTIVE WELL-BEING AND CITIZENSHIP DIMENSIONS}

Traditionally, Citizenship activity pertained to the relationships between the adults and the state. It was the subject of analyses in two scientific domains: political science and sociology. Post-modernism provides a new understanding of citizenship - it includes the idea of functioning in relation to everyday life, because contemporary global and local social problems (such as violence, terrorism and migration) can rarely be solved only by political regulations; more often their resolution requires everyday human activity (Kerr, 1999). This new concept of citizenship became a subject of other scientific areas (e.g. psychology - Lewicka, 2005) and allowed young people to be incorporated in the research (Koseła, 2005; Torney-Purta, Barber, \& Richardson, 2004), as they encounter such problems, too. Moreover, research on adolescents' citizenship activity seems to be particularly important since the young generation will have a great impact on social processes and the development of democracy in the future (Zalewska \& Krzywosz-Rynkiewicz, 2010). Zalewska and Krzywosz-Rynkiewicz (2011) proposed a broad model of Citizenship based on an earlier idea of Kennedy (Kennedy, 2007; Nelson \& Kerr, 2006). It was extended to all types of behaviour indicated by different taxonomies of Citizenship. This model includes the following six basic dimensions of citizenship:

- Passive citizenship including national identity (appreciating history, symbols and myths) and patriotism (supporting your country, military service, loyalty);

- Semi-active citizenship including loyalty (obeying the law and subordination to regulations, respect for the state) and citizen virtues mostly 
related to taking interest in public affairs and declared participation in elections (voting);

- Active citizenship related to four factors:

- Political Activity - declared participation in conventional political activity (e.g. running for office, being a member of a political party),

- Social Activity - participating in social movements and organizations, working for a local society, taking part in actions aimed at building and maintaining local community (e.g. representing the school),

- Change-oriented Activity - being committed to changing the status quo (petitioning, protests, street graffiti),

- Personal Activity - aimed at self-development, being responsible for oneself and one's future, striving for future financial independence and creative problem solving.

Findings from previous research indicate that the general pattern of Citizenship activity is similar among early, middle and late Polish adolescents (Zalewska \& Krzywosz-Rynkiewicz, 2011) as well as among Polish and other European adolescents (Krzywosz-Rynkiewicz \& Zalewska, 2015). Adolescents are the most willing to work towards personal development. They are also ready for Semi-active Citizenship (express willingness to vote in elections, be loyal to the law) and Passive Citizenship (sense of patriotism, respect for national symbols and loyalty to the state) to a high degree. Additionally, they are inclined to participate in social activities to a moderate degree but only slightly interested in participating in Political Activities as well as in Change-oriented Activity or in protests.

According to Zalewska and Krzywosz-Rynkiewicz (2011), this pattern can be explained by social evaluation of the Citizenship dimensions. Passive, Semi-active and Social Activity are oriented to the general common good, universally accepted and linked to each other to a moderate degree. Personal Activity is also highly valuated and related to the above-mentioned dimensions. Political Activity and Activity oriented for Change are weakly or not at all associated with the other Citizenship dimensions. Legal and desired behaviours included in the Political Activity dimension are not well respected in Poland, mostly because of the negative associations attributed to politicians' characteristics and behaviours (Kamińska-Szmaj, 2003). Change-oriented Activity is not always legal in its nature. It is related to the lack of acceptance of the present state of matters, protesting, striving for confrontation, change and having control over the authorities (Kennedy, 2007). Despite bringing positive outcomes (e.g. Solidarity movement), Change-oriented Activity is not universally accepted; it is often negatively defined as undesirable or even destructive behaviours.

In this paper we will analyse whether willingness to participate in various Citizenship activity is asso- ciated with SWB. The concept of SWB introduced by Diener (1984) refers to a broad spectrum of phenomena, which includes affective and cognitive appraisals of one's life. Affective evaluations expressed in momentary emotions (e.g. joy, guilt) represent current evaluations of the events, and those expressed in moods reflect more long-term influences (Diener, Suh, Lucas, \& Smith, 1999). Apart from affective reactions, SWB researchers are interested in cognitive evaluations, such as the level of basic needs satisfaction (Wilson, 1967), domain satisfaction and life satisfaction (Diener, Scollon, \& Lucas, 2003). Although each of these components has other antecedents (Diener, Suh, Lucas, \& Smith, 1999), they all correlate with one another and constitute a superordinate complex construct which can be called "subjective well-being", "happiness", "summary judgment of one's life" or "the subjective evaluation of one's life" (Diener, Scollon, \& Lucas, 2003; Oishi, Diener, \& Lucas, 2007).

Research on SWB consistently reveals that desirable life outcomes (valued by society) such as success, income, marriage, good job, health and long life correlate with different components of SWB. Although the researchers recognized that the causality can be bidirectional, they frequently assume that these desirable events (e.g. success) make people happy (Argyle, 1999; Diener, Suh, Lucas, \& Smith, 1999). Referring to three categories of evidence - cross-sectional, longitudinal and experimental - Lyubomirsky, King and Diener (2005) propose a new conceptual model for these findings. They argue that the happinesssuccess link exists not only because success makes people happy, but also because happiness causes success (see: Czapiński, 2004). Positive moods and emotions as components of SWB help prepare the organism for future challenges (Fredrickson, 2001). Happiness leads people to seek out others and to engage with the environment, to be more venturesome, more open, and more sensitive to other individuals (Veenhoven, 1988). Experiencing positive moods fosters helping behaviour and stimulates people to be more altruistic, generous and charitable, as well as to act in ways that promote resource building and engagement in approach goals (Lyubomirsky, 2001). In longitudinal research Thoits and Hewitt (2001) found that the causal connection between volunteer work and subjective well-being is bidirectional - those with high happiness and life satisfaction spent more time on volunteering activities and those who volunteered longer experienced an increase in happiness.

These data lead one to expect that SWB will facilitate readiness to undertake various Citizenship activities, except Political activity, because Oishi, Diener and Lucas (2007) found that links between SWB and political participation are not linear and those who experience slightly lower levels of happiness are the most successful in terms of income, education and political participation. 


\section{HORIZONTAL AND VERTICAL INDIVIDUALISM OR COLLECTIVISM AS INDIVIDUAL BELIEFS}

Individualism and Collectivism are concepts examined in different contexts within various social science fields (e.g. anthropology, management). They gained popularity due to research conducted by Hofstede $(1980,2000)$. He found that different cultures and nations occupy distinct positions on the Individualism-Collectivism continuum. For example, the US is considered an individualistic country, China a collectivistic one, and Poland is located in between Individualism and Collectivism but has gradually been moving toward Individualism for the past 20 years (Hofstede, 2000).

The Individualism-Collectivism dimension is considered as one of the cultural syndromes, understood as "a shared pattern of attitudes, beliefs, categorisations, self-definitions, norms, role definitions, orientations, and other subjective elements of culture that is organised around some theme" (Triandis, 2000, p. 13). "Individualism-collectivism dimension relates to the degree to which in a given culture needs, wishes, desires and orientations of the autonomous and unique self are respected and valued beyond needs, wishes, desires and orientations of the group" (Matsumoto \& Juang, 2007, p. 70). Therefore Individualism is defined as "a system of beliefs based on the assumption that an individual, his uniqueness and freedom is a measure of worth" (Wojciszke, 2011, p. 535); and collectivism is defined as "a system of beliefs based on the assumption that well-being of a group is more important than well-being of an individual" (Wojciszke, 2011, p. 536). In the individualistic cultures people are perceived as autonomous beings, and their personal goals are considered more significant than those of groups. Individual identity, built on one's successes and achievements, is more important than social identity, which entails group participation (Wojciszke, 2011). In the collectivistic cultures individuals feel a strong connection to the members of the group they belong to. They are willing to give up the pursuit of individual goals for the common good of the group and satisfaction of its needs (Markus \& Kitayama, 1991; in: Matsumoto \& Juang, 2007). Here, loyalty toward the group, respect for the group norms and good relationships with group members are highly valued (Wojciszke, 2011).

In contrast to the dichotomous concept of Hofstede (1980), Triandis (1995) and Singelis, Triandis, Bhawuk, and Gelfand (1995) offered a multidimensional definition of individualism and collectivism comprising 4 components of cultural orientation:

- Individualism defined by four characteristics independent self-construal, rationality and exchange relationships, attitudes as determinants of social behaviour, and personal goals;
- Collectivism also defined by four attributes - interdependent self-construal, relatedness and communal relationships, norms as determinants of social behaviour, and in-group goals;

- Horizontal orientation - underlying equality;

- Vertical orientation - emphasising hierarchy.

Based on the above, Triandis and Gelfand (1998) proposed four different patterns as a combination of the four components:

- Horizontal Individualism (HI) underlies self-independence, freedom and equality, striving to be distinct without desiring special status (e.g. social democracy in Australia or Sweden);

- Horizontal Collectivism (HC) emphasises self-interdependence, equality but not freedom, collaboration and empathy (e.g. the Israeli kibbutz);

- Vertical Individualism (VI) stresses competition, freedom but not equality, striving to be distinct while desiring special status (competitive capitalism and market economies such as in the United States);

- Vertical Collectivism(VC) emphasises interdependence and competition with out-groups; neither equality nor freedom is valued (traditional societies with strong leaders).

In psychology Horizontal and Vertical Individualism or Collectivism are also considered as individual beliefs, orientations or more specific individual-level context variables, that refer to the way the person defines himself or herself (self-construal) in relation to culture or to the social context (Matsumoto \& Kupperbusch, 2001). Culture-level analyses are conducted using indicators defining whole populations, e.g. gross domestic product per citizen, average life expectancy or the percentage of national income devoted to environmental protection (Triandis, 2000). In individual-level analyses indicators such as personal attitudes, beliefs or orientations are considered. The results of research conducted at the culture and individual levels can vary diametrically. For this reason Triandis, Leung, Villareal and Clarck (1985; in: Triandis, 2000) proposed two alternative concepts, idiocentrism and allocentrism, which could be used to describe personalities corresponding to both individualism and collectivism. Triandis (2000) presents an abundance of research confirming distinct relationships of individualism and idiocentrism with other variables. Verkuyten (1995) showed that although in the individualistic cultures idiocentrism and allocentrism are negatively correlated, in the collectivistic cultures they are independent of each other. The study presented in this paper was conducted in one culture, and we will analyse data only at the individual level, although we will use the terms individualism and collectivism like Robert, Probst, Martocchio, Drasgow and Lawler (2000), Górnik-Durose (2002) or Shavitt, Lalwani, Zhang and Torelli (2006) in their research. 


\section{INDIVIDUALISM OR COLLECTIVISM AND SUBJECTIVE WELL-BEING}

The data gathered in cross-cultural research indicate that individualistic cultures are happier than collectivistic ones (Diener \& Diener, 1995) and the judgement of happiness is anchored on other types of cues across cultures - in individualistic cultures happiness is more closely linked to psychological attributes of the self (e.g., self-esteem, optimism) than in collectivistic cultures (Suh \& Oishi, 2002). The more individualistic the nation was, the more strongly the life satisfaction judgments were based on internal emotions, but in collectivistic cultures satisfaction was predicted not only by emotions but also by behaviour consistent with social norms (Suh, Diener, Oishi, \& Triandis, 1998). Kitayama, Markus and Kurokawa (2000) discovered that in individualistic cultures higher level of satisfaction correlates with the experience of emotions such as pride or amusement, unrelated to interpersonal relationships. In collectivistic cultures however, people feel more satisfied while experiencing closeness, which is directly related to interpersonal relationships.

The way the person defines himself or herself (self-construal) in reference to the social context also influences the life satisfaction judgement (Suh, Diener, \& Updegraff, 2008) - those who view themselves in interdependent terms (allocentrics) evaluate their life satisfaction in a more collectivistic manner (reliance on social appraisal) than those who view themselves in independent terms (idiocentrics). There also exist some data on direct links between individualism and collectivism as individual beliefs and SWB in a given culture. Diener and Diener (1995) found that on an individual level of analysis the individualism-SWB link was negative. According to Triandis (1995), higher VI can lead to lower SWB because of the higher level of stress resulting from a strong tendency to rivalry and higher HI because of the higher level of loneliness and lower level of received social support. There are also data indicating a positive link between allocentrism and SWB, gathered by Verkuyten and Lay (1997, cited by Triandis, 2000) among minorities in the Netherlands, as well as findings obtained among American students by Battencourt and Dorr (1997). In the latter this link was mediated by collective self-esteem (positive valuation of own group by themselves and by others). However, a very important factor for SWB may be the person-culture fit; if personal characteristics are coherent with characteristics of culture, the self-esteem is higher, which leads to higher SWB (Triandis, 2000). Suh (2002) found similar data in North America - individuals more consistent with culture (with a higher Individualism index in an individualistic culture) manifested higher SWB and received positive social evaluations from others in the United States, but it was not the case in Korea.
RELATIONSHIPS BETWEEN SUBJECTIVE WELL-BEING, CITIZENSHIP DIMENSIONS AND HORIZONTAL/VERTICAL INDIVIDUALISM OR COLLECTIVISM - QUESTIONS AND HYPOTHESES

An important factor determining the influence of four beliefs on SWB is their acceptance in the society as well as consistency between self and what the culture regards as valuable (Suh, 2002). There is evidence that each of the four beliefs is positively related with other values: VI with achievement and power values, HI with autonomy and self-direction (freedom, equality), $\mathrm{HC}$ with social relations and benevolence (sociability, equality), and VC with conformity, associated with power distance (see Shavitt et al., 2006). As mentioned above, Poland occupies a middle position (Hofstede, 2000) on the collectivism-individualism dimension. Such a result probably does not mean that four beliefs as well as related values are equally important, but it probably indicates that the specific mixture of orientations is approved in Polish society. For example, in spite of the moderate range on individualism, Poland is rather high on power distance (House, Hanges, Javidan, Dorfman, \& Gupta, 2004) and relatively autocratic in leadership style, which suggests high VC (Maczynski, Jago, Reber, \& Boehnisch, 1994). Making comparisons of employees from the US, Poland, India and Mexico, Robert et al. (2000) found that Poland was high on VC (like India) and HI (like the US) but was in the middle on $\mathrm{HC}$ and VI (on both - like Mexico and higher than the US, p. 651). Being simultaneously high on both VC and HI may reflect respect for a mixture of both collectivism and individualism or high within-culture diversity - rather stable (other beliefs and related values are important in different social groups) or indicating the changing nature of Polish society (linked with age groups). On the basis of cluster analysis, Górnik-Durose (2002, p. 217) distinguished two groups among Polish and British students: individualists (60 of 102 [ca. 60\%] were Polish students) with dominant $\mathrm{HI}$ and the lowest VC, and collectivists (111 of 137 [over 80\%] were Polish) with dominant HC and the lowest VI. These data indicate that among the Polish students both Horizontal orientations dominate, although they still may reflect respect of students for a mixture of both Collectivism and Individualism.

Thus it can be assumed that a mixture of Collectivism and Individualism is approved in Polish society and as a result all beliefs will be positively associated with SWB. However, their influence on Citizenship dimensions will depend on the orientation of these dimensions: Citizenship dimensions oriented to general good (Social Activity, Passive and Semi-active Citizenship) will be associated with Collectivism beliefs and Citizenship dimensions including also personal benefits (personal growth, independence, specific status) 
like Personal and Political Activity will be associated with both Individualism and Collectivism. We formulated four research questions and several hypotheses:

Q1. What are the relations between the investigated beliefs, SWB and Citizenship dimensions?

H1.1. SWB will be positively associated with Citizenship dimensions except Political Activity.

H1.2. SWB will be associated with Individualism and Collectivism orientations.

H1.3. Collectivism beliefs ( $\mathrm{HC}$ and VC) will be positively associated with Citizenship dimensions oriented for the general good (Social Activity, Passive and Semi-active Citizenship).

H1.4. Collectivism and Individualism beliefs will be positively associated with Citizenship dimensions including personal benefits (Personal Activity and Political Activity).

As regards Change-oriented Activity the question remains open.

Q2. Which of the examined beliefs allow one to predict SWB?

This question also remains open, because the premises based on data presented by Diener and Diener (1995), Battencourt and Dorr (1997), Triandis (2000) and Suh (2002) are not conclusive.

Q3. Is the influence of beliefs on Citizenship dimensions mediated by SWB?

Although our research is designed as correlational, we assume that beliefs will influence SWB by other mechanisms (self-esteem, equality, freedom, success, social support, social identity) and that SWB will directly influence (as in the model of Lyubomirsky, King, \& Diener, 2005) readiness to undertake Activities belonging to Active Citizenship, especially Social and Personal Activity. Moreover, we also assume that Vertical orientations, as they incorporate hierarchy, will effect Citizenship independently of SWB. As a result we expect that SWB will mediate only the influence of Horizontal orientations (connected with equality) on Active Citizenship dimensions.

H3.1. Influence of Horizontal Collectivism on Social Activity will be mediated by SWB.

H3.2. Influence of Horizontal Individualism and Horizontal Collectivism on Personal Activity will be mediated by SWB.

Q4. Is the influence of SWB on Citizenship dimensions moderated by the orientations?

Taking into account that a high index of Vertical Collectivism means giving priority to the group over the individual, we suppose that it relates to the obligation to undertake actions for the common good independently of SWB. We expect that the influence of SWB on Citizenship dimensions oriented to the general good will be stronger when Vertical Collectivism is lower.

H4.1. Vertical Collectivism will moderate the influence of SWB on Citizenship dimensions oriented to the general good (Passive and Semi-active Citizen- ship, Social Activity) - the relations will be stronger if the value of the index is lower.

\section{PARTICIPANTS AND PROCEDURE}

Two hundred and nine second-year high school (111 students aged 17; 32 boys - 12 from a big city, 20 from a small town; 79 girls - 39 from a big city, 40 from a small town) and secondary school students (98 students aged 14; 49 boys - 25 from a big city, 24 from a small town, 49 girls - 19 from a big city, 30 from a small town) participated in the study. They were recruited in schools. The underage students took part in the research only with the consent of their parents or legal guardians. The research was approved by the Ethics Committee. The participants filled in the Horizontal and Vertical Individualism and Collectivism Questionnaire (H-V-In-Col 20), Citizenship Behaviour Questionnaire, and techniques for SWB measurement: Satisfaction with Life Scale, Subjective Happiness Scale, Ladder of Need Scales, and Mood Questionnaire.

\section{MEASURES}

The Horizontal and Vertical Individualism and Collectivism Questionnaire (H-V-In-Col 20, Triandis \& Gelfand, 1988) has 4 subscales, each with 5 items followed by answer scales from 1 (I strongly disagree) to 7 (I strongly agree):

Horizontal Individualism (HI) means equality, freedom and autonomy; it assesses the extent to which individuals strive to be distinct without desiring special status, (e.g. I often "do my own thing"); Cronbach's $\alpha=.63$.

Horizontal Collectivism (HC) means relationship-orientation and harmony; it assesses the extent to which individuals emphasize interdependence but also equality (e.g. The well-being of my co-workers is important to me); Cronbach's $\alpha=.60$.

Vertical Individualism (VI) means self-interest and competition; it assesses the extent to which individuals strive to be distinct and desire special status (e.g. It annoys me when other people perform better than I do); Cronbach's $\alpha=.71$.

Vertical Collectivism (VC) means priority of group goals, respect for elders and authorities; it assesses the extent to which individuals emphasize interdependence and competition with out-groups (e.g. I would sacrifice an activity that I enjoy very much if my family did not approve of it); Cronbach's $\alpha=.64$.

The Citizenship Behaviour Questionnaire ( $\mathrm{Za}-$ lewska \& Krzywosz-Rynkiewicz, 2011) is based on self-reports of adolescents on their everyday activities (what they do, what they intend to do). It consists of 34 questions, each followed by a 4-point answer 
scale $(1$ - definitely no, 2 - probably no, 3 - probably yes, 4 - definitely yes). It contains 6 scales with sufficient reliability to measure: Passive Citizenship -8 items, $\alpha=.88$ (Do you behave in a dignified and respectful way while listening to the Polish national anthem?); Semi-active Citizenship - 5 items, Cronbach's $\alpha=.64$ (Do you try to behave in accordance with the rules and regulations, e.g. at school?); Personal Activity -5 items, $\alpha=.73$ (Do you aspire to be financially independent, responsible for yourself and your own life?); Political Activity - 2 items, $\alpha=.77$ (When you turn 18, will you join a political party?); Social Activity - 10 items, $\alpha=.71$ (Do you know the members of the school council?); Change-oriented Activity -4 items, $\alpha=.79$ (Do you take part in any activities or protests that might lead to change, e.g. collecting signatures for petitions, blocking the streets, protesting by hanging posters or banners, occupying buildings, etc.?).

Satisfaction with Life Scale (Diener, Emmons, Larson, \& Griffin, 1985) consists of 5 items (e.g. In most ways my life is close to my ideal) with answers from 1 (I strongly disagree) to 7 (I strongly agree); Cronbach's $\alpha=.82$.

The Subjective Happiness Scale (Lyubomirsky \& Lepper, 1999) consists of 4 items (e.g. "In general, I consider myself”) with scales ranging from 1 to 7 with different variants of the answer (e.g. 1 - not a very happy person; 7 - a very happy person) and the $4^{\text {th }}$ item reversely coded; Cronbach's $\alpha=.81$.

The Ladder of Need Scales allow one to measure satisfaction with 5 universal needs (basic existence needs, health, affiliation and love, respect, self-actualization) with 0-10 scales; the sum of scores is an index of needs satisfaction; Cronbach's $\alpha=.80$.

The Mood Questionnaire by Zalewska has three subscales for measuring frequency (from 0 - never, to 6 - every day) of affective reactions connected with three dimensions of mood: pleasure (e.g. happy, sad), energy (e.g. lively, tired) and tension (e.g. composed, stressed). Each subscale consists of 8 items (4 with reverse code). Cronbach's $\alpha$ for: Pleasure $=.64$, Energy $=.70$, Tension $=.66$.

Although we measured different components of SWB in our research, the present paper will only analyse the index of the superordinate construct of SWB understood as a summary judgment of one's life (Oishi et al., 2007). It was distinguished in principal component analysis (with eigenvalue $3.53>1$ ) designed for all components of SWB mentioned above. It explained $58.76 \%$ of variance of all components and was written as a regression function for all of them.

\section{RESULTS}

In order to answer the question about simple relations between investigated constructs, correlational analyses were performed. Their results, presented in Table 1, show that four beliefs were relatively independent. Moderate correlations occurred between both Collectivism dimensions (.40) and both Individualism dimensions (.34), but links between $\mathrm{HI}$ and both Collectivism dimensions were weak and positive, and those between VI and these two dimensions were close to zero and not significant. Also correlations between Citizenship dimensions were weak or moderate (-.01 to .47).

The data fully confirm Hypothesis H1.1 about positive relations between SWB and Citizenship dimensions - all these correlations were positive and significant, excluding political activity. SWB was moderately and positively associated with Horizontal (HI and $\mathrm{HC}$ ) and Collectivism orientations (HC and VC). These data only partly confirm hypothesis H1.2, because Vertical Individualism (VI) was not associated with SWB.

The results in Table 1 also indicate that Citizenship dimensions oriented to general good (Social Activity, Passive and Semi-active Citizenship) were associated with both Collectivism beliefs (HC and VC), which confirms H1.3, and they did not correlate with Individualism. Citizenship dimensions including personal benefits (Personal Activity and Political Activity) were positively linked to $\mathrm{HI}$ and VC. Personal activity was also positively linked to $\mathrm{HC}$, as was expected according to H1.4, but they were not correlated with VI (Table 2).

In relation to the question (Q2) about beliefs as predictors of SWB, a regression analysis on standardized scores with the stepwise method was designed. Its results indicated that the best predictor of SWB among adolescents was $\mathrm{HC}$, which alone explained over $20.00 \%$ of variance of SWB. All four dimensions were significant predictors of SWB (together explaining $33.30 \%$ ), although the simple (zero-level) correlation between SWB and VI was not significant. When the influence of each belief was controlled for, even VI added significantly to the explanation of SWB, but its higher index predicted lower SWB.

In relation to questions Q3 (Is the influence of beliefs on Citizenship dimensions mediated by SWB?) and Q4 (Is the influence of SWB on Citizenship dimensions moderated by the beliefs?), six hierarchical regression analyses were conducted, each for one dimension of Citizenship separately. In each analysis 3 models were designed: in the first model all the beliefs were introduced, in the second SWB was added, and products of beliefs and SWB were included in the third model. The results presented in Table 3 show that:

1) The data partly confirm H4.1, because the product of SWB and VC tended to be significant only for Passive and Semi-active Citizenship, but not significant for Social Activity. The negative value of Beta indicated that relations between SWB and 


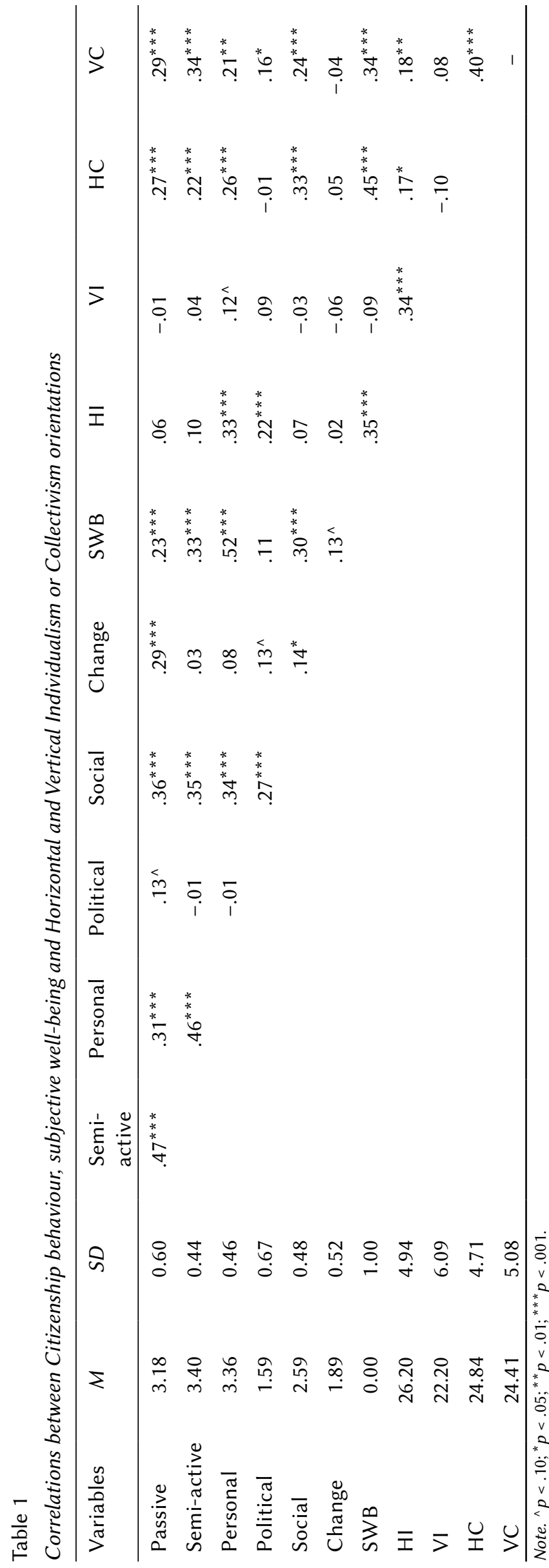

these dimensions (for Passive Citizenship $r=.22$, $p=.027$ and for Semi-Active Citizenship $r=.38$, $p<.001$ ) were stronger if VC was lower (correlations for Passive $r=.07$ and Semi-Active Citizenship $r=.14$ were not significant if the VC index was higher).

2) In relation to Social Activity, introducing SWB into the analysis in Model 2 diminished the beta value of $\mathrm{HC}$ and the Sobel test (value $=2.19, p=.028$ ) confirmed the significance of partial SWB mediation in the relation between $\mathrm{HC}$ and Social Activity. Although introducing SWB also diminished the beta value of VC, the Sobel test (value $=1.75, p=.080$ ) was not significant. These results fully confirmed Hypothesis H3.1.

3) Regarding Personal Activity, the data fully confirmed H3.2. Introducing SWB into the analysis diminished the beta value of $\mathrm{HI}$ and $\mathrm{HC}$ and the Sobel test (value $=4.17, p<.001$ for $\mathrm{HI}$ and value $=$ $3.96, p<.001$ for HC) confirmed SWB mediation in relations between these beliefs and Personal Activity.

4) Political Activity was predicted only by indices of two beliefs, HI and VC; it was independent of SWB and products of SWB with beliefs.

5) Activity for Change tended to be higher only with higher SWB.

6) VI did not predict any Citizenship dimension.

\section{DISCUSSION}

This research provides a unique set of data, contributing to understanding of the relationship between the Horizontal/Vertical Individualism and Collectivism, SWB and citizenship behaviours of Polish youth living in the culture "in between individualism and collectivism".

The results of correlational analyses showed that four dimensions of orientations were relatively independent, which confirmed the validity of its multidimensional conception. Moreover, links between HI and both Collectivism dimensions were weak and positive, and those between VI and these two dimensions were close to zero. According to Verkuyten (1995), such results are typical for collectivistic cultures, so in this context we can conclude that young Poles live in a more collectivistic than an individualistic society.

We found that Passive, Semi-active and Social Activity were linked to each other to a moderate degree. Personal Activity was also positively associated with the above-mentioned dimensions. Political Activity and Change-oriented Activity were weakly or not associated with the other Citizenship dimensions. This pattern of correlations confirmed the validity of multidimensional conception of Citizenship and was similar to that obtained for early, middle and late adolescents (Zalewska \& Krzywosz-Rynkiewicz, 2011). 
Table 2

Horizontal and Vertical Individualism or Collectivism orientations as predictors of subjective well-being results of regression analysis on standardized scores (stepwise method)

\begin{tabular}{lcccc}
\hline Predictor & $B$ & $S E$ & $\beta$ & $\Delta R^{2}$ \\
\hline Horizontal Collectivism & .44 & .06 & $.45^{* * *}$ & $.21^{* * *}$ \\
Horizontal Collectivism & .40 & .06 & $.41^{* * *}$ & $.29^{* * *}$ \\
Horizontal Individualism & .29 & .06 & $.38^{* * *}$ & $.35^{* * *}$ \\
Horizontal Collectivism & .37 & .06 & $-.18^{* *}$ & $.03^{* *}$ \\
Horizontal Individualism & .35 & .06 & $.31^{* * *}$ & $.34^{* * *}$ \\
Vertical Individualism & -.18 & .06 & $-.19^{* *}$ & $.16^{*}$ \\
Horizontal Collectivism & .31 & .06 & $.02^{*}$ \\
Horizontal Individualism & .34 & .06 & .06 & \\
Vertical Individualism & -.19 & .06 & .06 & \\
Vertical Collectivism & -.003 & $.5(4,205)=25.56, p<.001$. &
\end{tabular}

The obtained data confirm positive links between SWB and Citizenship dimensions except Political Activity. That is in accordance with data indicating that the link between SWB and political participation is not linear and the happiest people are not those most willing to engage in Politics (Oishi, Diener, \& Lucas, 2007).

These results provide an additional argument supporting the hypothesis that SWB positively correlates with desirable positive activities (Lyubomirsky, King, \& Diener, 2005), universally accepted Citizenship dimensions oriented for the general good such as Social, Passive and Semi-Active Citizenship. They are also consistent with data collected by Veenhoven (1988) showing that SWB facilitated engagement in the social environment, being more open and venturesome (Social and Change-oriented Activity), as well as with data obtained by Fredrickson (2001) and Lyubomirsky (2001) indicating that happiness promotes actions oriented to building personal resources (Personal Activity). Summing up, the data confirm positive links of pleasant life (SWB) with meaningful life (Citizenship dimensions).

In this research SWB was positively associated with both Horizontal (HI, HC - emphasizing equality), and both Collectivism beliefs (HC, VC), associated with interdependent self-construal, relatedness, norms, and in-group goals. The first and best predictor of SWB among the Polish adolescents was HC (relationship-orientation, collaboration, empathy, sociability, harmony). Such results are in accordance with data indicating a positive link between allocentrism and SWB, which is probably mediated by a level of social support and collective self-esteem (Battencourt \& Dorr, 1997; Triandis, 2000).
These results give additional insight into relations between Individualism and SWB among young Poles. It was found that HI (equality, freedom, autonomy) was beneficial for their SWB as idiocentrism was for SWB of Americans living in individualistic culture (Suh, 2002). Only VI, associated with self-interest and competition, was not linked with SWB in simple analysis (VI was suppressed by HI due to a positive relation with it - Cichocka \& Bilewicz, 2010), but its higher index predicted lower SWB, while HI and Collectivism beliefs were controlled. This relation is similar to findings obtained by Diener and Diener (1995) and can be explained by a higher level of stress resulting from a stronger tendency to rivalry (Triandis, 2000).

The findings also shed light on the complex mechanisms shaping Citizenship dimensions (each has different predictors) of the young Poles. They strongly confirmed that the relations of Individualism and Collectivism with Citizenship dimensions were dependent on the orientation of these dimensions: Citizenship dimensions oriented to general good (Social Activity, Passive and Semi-active Citizenship) were associated with Collectivism beliefs and Citizenship dimensions also including personal benefits (personal growth, independence, specific status) like Personal and Political Activity were associated with $\mathrm{HI}$ and Collectivism beliefs. VI associated with self-interest and competition did not contribute to predicting any Citizenship dimension.

The results also proved that SWB mediated relations only between Horizontal orientations (emphasizing equality) and Active Citizenship dimensions - the higher were the Horizontal orientations, the higher was SWB, and the higher was SWB, the higher was Personal or Social Activity. VC (emphasizing 
Table 3

Horizontal and Vertical Individualism or Collectivism orientations, subjective well-being and their products as predictors of Citizenship dimensions - results of hierarchical regression analyses on standardized scores

\begin{tabular}{|c|c|c|c|c|c|c|}
\hline Models/Variables & Passive & Semi-active & Social & Personal & Political & Change \\
\hline Model 1 & $\Delta R^{2}=.11^{* * *}$ & $\Delta R^{2}=.12^{* * *}$ & $\Delta R^{2}=.12^{* * *}$ & $\Delta R^{2}=.16^{* * *}$ & $\Delta R^{2}=.07^{* *}$ & $\Delta R^{2}=.01$ \\
\hline Horizontal Ind & -.01 & .02 & .01 & $.27^{* * *}$ & $.21^{* *}$ & .04 \\
\hline Vertical Ind & -.01 & .02 & -.01 & .03 & -.00 & -.06 \\
\hline Horizontal Col & $.18^{*}$ & .11 & $.27^{* * *}$ & $.18^{*}$ & -.11 & .06 \\
\hline Vertical Col & $.22^{* *}$ & $.29^{* * *}$ & $.13^{\wedge}$ & .09 & $.17^{*}$ & -.06 \\
\hline Model 2 & $\Delta R^{2}=.01$ & $\Delta R^{2}=.05^{* * *}$ & $\Delta R^{2}=.03^{*}$ & $\Delta R^{2}=.15^{* * *}$ & $\Delta R^{2}=.001$ & $\Delta R^{2}=.02^{\wedge}$ \\
\hline Horizontal Ind & -.04 & -.07 & -.06 & $.12^{\wedge}$ & $.20^{*}$ & -.01 \\
\hline Vertical Ind & .01 & .07 & .02 & $.12^{\wedge}$ & .01 & -.04 \\
\hline Horizontal Col & $.15^{\wedge}$ & .02 & $.21^{* *}$ & .04 & -.12 & .01 \\
\hline Vertical Col & $.20^{* *}$ & $.25^{* * *}$ & .10 & .01 & $.16^{*}$ & -.09 \\
\hline SWB & .11 & $.27^{* * *}$ & $.20^{*}$ & $.47^{* * *}$ & .04 & $.16^{\wedge}$ \\
\hline Model 3 & $\Delta R^{2}=.04^{\wedge}$ & $\Delta R^{2}=.04^{\wedge}$ & $\Delta R^{2}=.01$ & $\Delta R^{2}=.004$ & $\Delta R^{2}=.03$ & $\Delta R^{2}=.03$ \\
\hline Horizontal Ind & -.06 & -.04 & & & & \\
\hline Vertical Ind & .03 & .08 & & & & \\
\hline Horizontal Col & $.16^{*}$ & -.01 & & & & \\
\hline Vertical Col & $.20^{* *}$ & $.22^{* *}$ & & & & \\
\hline SWB & .12 & $.25^{* *}$ & & & & \\
\hline SWB $x$ Horizontal Ind & -.01 & .06 & & & & \\
\hline SWB $\times$ Vertical Ind & -.09 & -.12 & & & & \\
\hline SWB $\times$ Horizontal Col & .08 & -.08 & & & & \\
\hline SWB $\times$ Vertical Col & $-.15^{\wedge}$ & $-.14^{\wedge}$ & & & & \\
\hline Constant & 3.17 & 3.42 & 2.63 & 3.39 & 1.59 & 1.93 \\
\hline Total $R^{2}$ & $.16^{* * *}$ & $.21^{* * *}$ & $.15^{* * *}$ & $.31^{* * *}$ & $.10^{* *}$ & .06 \\
\hline$N$ & 209 & 209 & 209 & 209 & 209 & 209 \\
\hline
\end{tabular}

Note. ${ }^{\wedge} p<.10 ;{ }^{*} p<.05 ;{ }^{* *} p<.01 ;{ }^{* *} p<.001$.

hierarchy) influenced Citizenship independently of SWB. Finally, they showed that VC moderated relations between SWB and more passive Citizenship dimensions oriented to general good (Passive and Semi-active Citizenship) - the relations were not significant when the VC index was high. These results can be explained by the fact that higher VC means priority of group goals and a stronger sense of obligation to undertake actions for the common good independently of the level of SWB (I should obey the regulation even if I am unhappy). When VC is lower, the obligation is smaller, and then the actions oriented to the general good depend to a higher degree on the level of SWB. In other words, among young Poles higher Horizontal orientations facilitate flourishing - achieving higher levels of both pleasant and some aspects of meaningful life. However, higher $\mathrm{VC}$ can hinder the coherence between pleasant and meaningful life - some people can develop meaningful life (more passive Citizenship) even if their pleasant life is low.

Antecedents of two Citizenship dimensions still remained relatively unknown because Political Activity was predicted only to a small degree $(7.40 \%$ of variance) by two orientations, $\mathrm{HI}$ and $\mathrm{VC}$, and Activity for Change (2.60\% of variance) was marginally predicted by SWB. It would be beneficial to include other personality variables and a wider age range of young people (e.g. university students) in further analyses. However, the main limitation of this study is the correlational approach. Longitudinal research will allow real temporal associations between SWB and Citizenship to be found, because civic engagement and volunteering can have positive effects on later SWB (Thoits \& Hewitt, 2001; Son \& Wilson, 2012). 


\section{CONCLUSIONS}

Among the Polish adolescents, pleasant life (SWB) has been positively linked to meaningful life (Citizenship dimensions). Individualism (HI, VI) and Collectivism (HC, VC) orientations are relatively independent, and their relations with SWB and Citizenship dimensions are complex. Higher Vertical Individualism predicts lower SWB but is not linked with Citizenship. Horizontal (equality) and Collectivism (interdependent self-construal) orientations influence SWB. However, higher Horizontal orientations facilitate flourishing (achieving higher both pleasant and some aspects of meaningful life), but higher Vertical Collectivism can hinder the coherence between pleasant and meaningful life - some people can develop meaningful life (more passive Citizenship) even if they experience rather low pleasant life. It is important to study what variables increase SWB, engagement in Citizenship behaviour and links between them, because all of them are necessary to attain "authentic happiness" and experience living a truly full life. In further analyses, additional variables such as personality traits, sex, age or size of the community population should be taken into account in order to extend the knowledge about these complex relations and their potential moderators.

\section{FUNDING SOURCE}

Research funded by National Science Centre Grant No. OPUS 2013/11/B/HS6/01135.

\section{REFERENCES}

Argyle, M. (1999). Causes and correlates of happiness. In D. Kahneman, E. Diener, \& N. Schwarz (eds.), Well-being: The foundations of hedonic psychology (pp. 353-373). New York, NY, US: Russell Sage Foundation.

Bettencourt, B. A., \& Dorr, N. (1997). Collective selfesteem as a mediator of the relationship between allocentrism and subjective well-being. Personality and Social Psychology Bulletin, 23, 963-972.

Cichocka, A., \& Bilewicz, M. (2010). Co się kryje w nieistotnych efektach statystycznych? Możliwości zastosowania analizy supresji w psychologii społecznej [What is hidden in nonsignificant effects? Application of suppression analysis in social psychology]. Psychologia Spoteczna, 52-53, 191-198.

Czapiński, J. (2004). Czy szczęście popłaca? Dobrostan psychiczny jako przyczyna pomyślności życiowej [Do everything come to those who are happy? Psychological well-being as a cause of life prosperity]. In J. Czapiński (ed.), Psychologia pozytywna. Nauka o szczęściu, zdrowiu, sile i cnotach czlowieka [Positive psychology. The science on happiness, health, strength, and virtues of a man] (pp. 235-254). Warszawa: Wydawnictwo Naukowe PWN.

Diener, E. (1984). Subjective well-being. Psychological Bulletin, 95, 542-575.

Diener, E., \& Diener, M. (1995). Cross-cultural correlates of life satisfaction and self-esteem. Journal of Personality and Social Psychology, 68, 653-663.

Diener, E., Emmons, R. A., Larson, R. J., \& Griffin, S. (1985). The satisfaction with life scale. Journal of Personality Assessment, 49, 71-75.

Diener, E., Scollon, C. N., \& Lucas, R. E. (2003). The evolving concept of subjective well-being: The multifaceted nature of happiness. Advances in Cell Aging and Gerontology, 15, 187-219.

Diener, E., Suh, E. M., Lucas, R. E., \& Smith, H. L. (1999). Subjective well-being: Three decades of progress. Psychological Bulletin, 125, 276-302.

Fredrickson, B. L. (2001). The role of positive emotions in positive psychology: The broaden-andbuild theory of positive emotions. American Psychologist, 56, 218-226.

Górnik-Durose, M. (2002). Psychologiczne aspekty posiadania - między instrumentalnościq a spotecznq użytecznościa dóbr materialnych [Psychological aspects of property]. Katowice: Wydawnictwo Uniwersytetu Śląskiego.

Hofstede, G. (1980). Culture's Consequences: International Differences in Work-Related Orientations. Beverly Hills CA: Sage Publications.

Hofstede, G. (2000). Kultury i organizacje [Cultures and Organizations]. Warszawa: Polskie Wydawnictwo Ekonomiczne.

House, R. J., Hanges, P. J., Javidan, M., Dorfman, P., \& Gupta, V. (eds.). (2004). Culture, Leadership, and Organizations: The GLOBE Study of 62 Societies. Thousand Oaks: Sage Publications.

Kamińska-Szmaj, I. (2003). Człowiek zwierzęciem politycznym [Man - a political animal]. Acta Universitatis Wratislaviensis, 15, 135-141.

Kennedy, K. J. (2007), Student construction of 'active citizenship': What does participation mean to students? British Journal of Educational Studies, 55, 304-324.

Kerr, D. (1999). Citizenship Education: an International Comparison. London: QCA.

Kitayama, S., Markus, H. R., \& Kurokawa, M. (2000). Culture, emotion, and well-being: Good feelings in Japan and the United States. Cognition and Emotion, 14, 93-124.

Koseła, K. (2005). Młodzi Polacy i mtodzi Niemcy $w$ nowej Europie [Young Polish people and young Germans in new Europe]. Warszawa: IFiS PAN.

Krzywosz-Rynkiewicz, B., \& Zalewska, A. M. (2015). Aktywność obywatelska polskiej młodzieży w relacji do innych Europejczyków i w zależności od fazy adolescencji [Ctizenship activity of Polish youth in 
relation to other young Europeans and adolescence stages]. Psychologia Rozwojowa, 20, 11-23.

Lewicka, M. (2005). Ways to make people active: The role of place attachment, cultural capital, and neighborhood ties. Journal of Environmental Psychology, 25, 381-395.

Lyubomirsky, S. (2001). Why are some people happier than others?: The role of cognitive and motivational processes in well-being. American Psychologist, 56, 239-249.

Lyubomirsky, S., King, L., \& Diener, E. (2005). The benefits of frequent positive affect: Does happiness lead to success? Psychological Bulletin, 131, 803-855.

Lyubomirsky, S., \& Lepper, H. (1999). A measure of subjective happiness: Preliminary reliability and construct validation. Social Indicators Research, 46, 137-155.

Maczynski, J., Jago, A. G., Reber, G., \& Boehnisch, W. (1994). Culture and leadership styles: A comparison of Polish, Austrian, and U.S. managers. Polish Psychological Bulletin, 25, 303-315.

Matsumoto, D., \& Juang, L. (2007). Psychologia międzykulturowa [Cross-cultural psychology]. Gdańsk: GWP.

Matsumoto, D., \& Kupperbusch, C. (2001). Idiocentric and allocentric differences in emotional expression, experience, and the coherence between expression and experience. Asian Journal of Social Psychology, 4, 113-131.

Nelson, J., \& Kerr, D. (eds.). (2006). Active Citizenship in INCA Countries: definitions, policies, practices and outcomes. London: QCA.

Oishi, S., Diener, E., \& Lucas, R. E. (2007). The Optimum Level of Well-Being: Can People Be Too Happy? Perspectives on Psychological Science, 2, 346-360.

Robert, C., Probst, T., Martocchio, J. J., Drasgow, F., \& Lawler, J. J. (2000). Empowerment and Continuous Improvement in the United States, Mexico, Poland, and India: Predicting Fit on the Basis of the Dimensions of Power Distance and Individualism. Journal of Applied Psychology, 85, 643-658. doi: 10.1037//0021-9010.85.5.643

Seligman, M. E. P. (2002). Authentic Happiness. New York: Free Press.

Seligman, M. E. P. (2011). Flourish. A Visionary New Understanding of Happiness and Well-Being. New York: Free Press.

Shavitt, S., Lalwani, A. K., Zhang,J., \& Torelli,C.J.(2006). The Horizontal/Vertical Distinction in CrossCultural Consumer Research. Journal of Consumer Psychology, 16, 325-356.

Singelis, T. M., Triandis, H. C., Bhawuk, D. P. S., \& Gelfand, M. J. (1995). Horizontal and vertical dimensions of individualism and collectivism: A theoretical and measurement refinement. Cross-Cultural Research, 29, 240-275. doi: 10.1177/106939719502900302
Son, J., \& Wilson, J. (2012). Volunteer work and hedonic, eudemonic, and social wellbeing. Sociological Forum,27,658-681.doi: 10.1111/j.15737861.2012.01340

Suh, E. M. (2002). Culture, identity consistency, and subjective well-being. Journal of Personality and Social Psychology, 86, 1378-1391.

Suh, E., Diener, E., Oishi, S., \& Triandis, H. C. (1998). The shifting basis of life satisfaction judgments across cultures: Emotions versus norms. Journal of Personality and Social Psychology, 74, 482-493.

Suh, E. M., Diener, E., \& Updegraff, J. A. (2008). From culture to priming conditions. Self-Construal Influences on Life Satisfaction Judgments. Journal of Cross-Cultural Psychology, 39, 3-15. doi: 10.1177/0022022107311769

Suh, E. M., \& Oishi, S. (2002). Subjective well-being across cultures. In W. J. Lonner, D. L. Dinnel, S. A. Hayes, \& D. N. Sattler (eds.), Online Readings in Psychology and Culture (Unit 7, Chapter 1), Center for Cross-Cultural Research, Western Washington University, Bellingham, Washington USA.

Thoits, P. A., \& Hewitt, L. N. (2001). Volunteer work and well-being. Journal of Health and Social Behavior, 42, 115-131.

Torney-Purta, J., Barber, C. H., \& Richardson W. K. (2004). Trust in Government-Related Institutions and Political Engagement among Adolescents in Six Countries. Acta Politica, 39, 380-406.

Triandis, H. C. (1995). Individualism and collectivism. Boulder, CO: Westview Press.

Triandis, H. C. (2000). Cultural syndromes and subjective well-being. In E. Dienier \& E. M. Suh (eds.), Culture and subjective well-being (pp. 13-36). Cambridge, MA: The MIT Press.

Triandis, H. C., \& Gelfand, M. J. (1998). Converging Measurement of Horizontal and Vertical Individualism and Collectivism. Journal of Personality and Social Psychology, 74, 118-128.

Veenhoven, R. (1988). The utility of happiness. Social Indicators Research, 20, 333-354.

Verkuyten, M. (1995). Self-esteem, self-concept stability, and aspects of ethnic identity among minority and majority youth in the Netherlands. Journal of Youth and Adolescence, 24, 155-175.

Wilson, W. (1967). Correlates of avowed happiness. Psychological Bulletin, 67, 294-306.

Wojciszke, B. (2011). Psychologia spoteczna [Social Psychology]. Warszawa: Wydawnictwo Naukowe Scholar.

Zalewska, A. M., \& Krzywosz-Rynkiewicz B. (2010), Optimism and readiness for citizenship activity. In B. Krzywosz-Rynkiewicz, A. Zalewska, \& A. Ross (eds.), Future Citizens: $21^{\text {st }}$ century challenges for young people (pp. 305-332). Kraków: Impuls.

Zalewska, A. M., \& Krzywosz-Rynkiewicz B. (2011). Psychologiczne portrety mtodych obywateli [Psychological portraits of young citizens]. Warszawa: Wydawnictwo SWPS Academica. 